\title{
Calmodulin binding proteins and neuroinflammation in multiple neurodegenerative diseases
}

Danton H. O'Day ${ }^{1,2}$ and Robert J. Huber ${ }^{3^{*}}$ (D)

\begin{abstract}
Calcium dysregulation ("Calcium Hypothesis") is an early and critical event in Alzheimer's and other neurodegenerative diseases. Calcium binds to and regulates the small regulatory protein calmodulin that in turn binds to and regulates several hundred calmodulin binding proteins. Initial and continued research has shown that many calmodulin binding proteins mediate multiple events during the onset and progression of Alzheimer's disease, thus establishing the "Calmodulin Hypothesis". To gain insight into the general applicability of this hypothesis, the involvement of calmodulin in neuroinflammation in Alzheimer's, amyotrophic lateral sclerosis, Huntington's disease, Parkinson's disease, frontotemporal dementia, and other dementias was explored. After a literature search for calmodulin binding, 11 different neuroinflammatory proteins (TREM2, CD33, PILRA, CR1, MS4A, CLU, ABCA7, EPHA1, ABCA1, CH3L1/YKL40 and NLRP3) were scanned for calmodulin binding domains using the Calmodulin Target Database. This analysis revealed the presence of at least one binding domain within which visual scanning demonstrated the presence of valid binding motifs. Coupled with previous research that identified 13 other neuroinflammation linked proteins (BACE1, BIN1, CaMKII, PP2B, PMCA, NOS, NMDAR, AchR, Ado A2AR, Aß, APOE, SNCA, TMEM175), this work shows that at least 24 critical proteins involved in neuroinflammation are putative or proven calmodulin binding proteins. Many of these proteins are linked to multiple neurodegenerative diseases indicating that calmodulin binding proteins lie at the heart of neuroinflammatory events associated with multiple neurodegenerative diseases. Since many calmodulinbased pharmaceuticals have been successfully used to treat Huntington's and other neurodegenerative diseases, these findings argue for their immediate therapeutic implementation.
\end{abstract}

Keywords: Neurodegeneration, Neuroinflammation, Calmodulin binding proteins, Calmodulin binding domains, Calcium, IQ motifs

\section{Background}

At least three common themes appear to underlie all well-studied neurodegenerative diseases: disruptive protein deposits, calcium dysregulation and neuroinflammation. The result is the dysfunction or loss of neurons in disease-specific regions of the brain. Increasing evidence

\footnotetext{
${ }^{*}$ Correspondence: roberthuber@trentu.ca

${ }^{3}$ Department of Biology, Trent University, 1600 West Bank Drive,

Peterborough, ON K9L OG2, Canada

Full list of author information is available at the end of the article
}

argues that neuroinflammation is an early and critical event not only in Alzheimer's disease (AD), where it has been extensively studied, but also in other neurodegenerative diseases including amyotrophic lateral sclerosis (ALS), frontotemporal dementia (FTD), Huntington's disease (HD), Parkinson's disease (PD), Lewy Body dementia (LBD), Batten disease (BD) and others [3, 6, $7,46,58,60]$. Neuroinflammation is a multistage process mediated mainly by microglia and astrocytes in the brain and influenced by external input (e.g., [20, 22, 23]. Chronic or unregulated neuroinflammation can lead to 
the uncontrolled release of pro-inflammatory factors that interfere with neuronal repair, cause synaptic impairment, mitochondrial dysfunction and disruption of the blood-brain barrier augmenting the neurodegenerative process [56].

Early and continued research first revealed the importance of dysregulated calcium levels in the events of $\mathrm{AD}$ leading to the Calcium Hypothesis [31, 32, 48]. The small calcium-binding protein calmodulin $(\mathrm{CaM})$ is a primary effector of calcium function and works in turn by binding to and regulating CaM-binding proteins (CaMBPs) [53]. The Calcium Hypothesis was thus extended as the Calmodulin Hypothesis since CaM not only binds to and regulates CaMBPs critical to learning and memory but also proteins involved in the formation of amyloid plaques and tangles, hallmarks of AD [41]. Calcium dysregulation is also common to other neurodegenerative events [27]. CaM was subsequently shown to regulate many risk factor proteins, glutamate receptors (mGluR, NMDAR), ryanodine receptors, the adenosine $\mathrm{A} 2 \mathrm{~A}$ receptor, as well as other critical proteins linked to the onset and progression of $\mathrm{AD}$ and other neurodegenerative diseases [4, 9, 42-44]. The intimate role of CaMBPs in AD was recently reviewed reinforcing the role of $\mathrm{CaM}$ in binding to and regulating multiple key proteins adding further support for the Calmodulin Hypothesis of O'Day and Myre [41, 47]. However, one area that remains to be investigated is neuroinflammation.

Summarizing the work of others, Hampel et al. [22] noted that Genome Wide Association Studies (GWAS) identified multiple protein variants involved in $\mathrm{AD}$ neuroinflammation: triggering receptor expressed on myeloid cells 2 (TREM2), myeloid cell surface antigen CD33 (CD33), paired immunoglobin-like type 2 receptor alpha (PILRA), complement receptor type 1 (CR1), membrane-spanning 4-domains subfamily A (MS4A), clusterin (CLU), ATP-binding cassette subfamily A member 7 (ABCA7), and ephrin type-A receptor 1 (EPHA1). In addition, ATP-binding cassette subfamily A member 1 (ABCA1), chitinase-3-like protein I (CH3L1/YKL-40), and NACHT, LRR and PYD domains-containing protein 3 (NLRP3) are neuroinflammatory biomarkers linked to AD $[1,19,50]$. Several of these and other neuroinflammatory proteins have also been studied in LBD, HD, PD, and FTD [20, 37, 46, 55, 60,64]. The critical function of ABCA7 in AD and FTD was recently reviewed [38]. Major risk factors for late-onset AD, CLU and CD33, are also involved in PD and multiple sclerosis (MS) [35, 54]. To gain insight into the potential role of $\mathrm{CaM}$ in neuroinflammation, we performed a literature search to determine if CaM-binding had been experimentally verified for any of these proteins and if any CaMBDs had been revealed. The remaining proteins, with sequences taken from the Uniprot database (www.uniprot.org), were subjected to a Calmodulin Target Database (http://calcium. uhnres.utoronto.ca/ctdb/no_flash.htm) search for the presence of putative CaMBDs [65] (Fig. 1). The Calmodulin Target Database uses Profile Hidden Markov Model algorithms and is recognized as the "dominant" method and "gold standard" for predicting CaM-binding, especially for proteins over 100 amino acids in length [39, 63]. Putative CaMBDs were then scanned visually to detect different binding motifs [41, 44, 51, 59] (Fig. 2). A priori, the greater the number of binding motifs argues the CaMBD has a higher chance of being a true binding domain. It should be noted that the Calmodulin Target Database primarily detects canonical, calcium-dependent CaMBDs leaving less common non-canonical and IQ motifs undetected. While non-canonical calciumdependent CaMBDs can only be discovered through experimental means, calcium-independent IQ motifs can be detected through visual scanning of amino acid sequences thus setting the stage for their experimental validation.

\section{Main text \\ Detection of putative calmodulin binding domains in proteins associated with neuroinflammation}

Using the Calmodulin Target Database, calcium-dependent CaMBDs were identified in 11 proteins linked to neuroinflammation: ABCA7, CD33, CH3L I, CLU, CR1, EPHA1, MS4A4E, MS4A6A, NLRP3, PILRA, TREM2

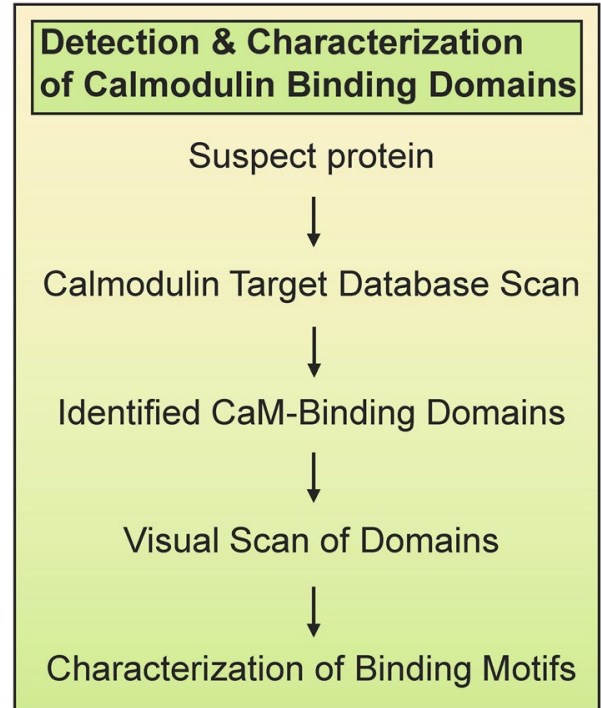

Fig. 1 Sequence of steps involved in evaluating calmodulin binding domains in suspect proteins. Putative domains and binding motifs in suspect proteins were determined by performing a Calmodulin Target Database scan followed by a visual scan of the identified domains 


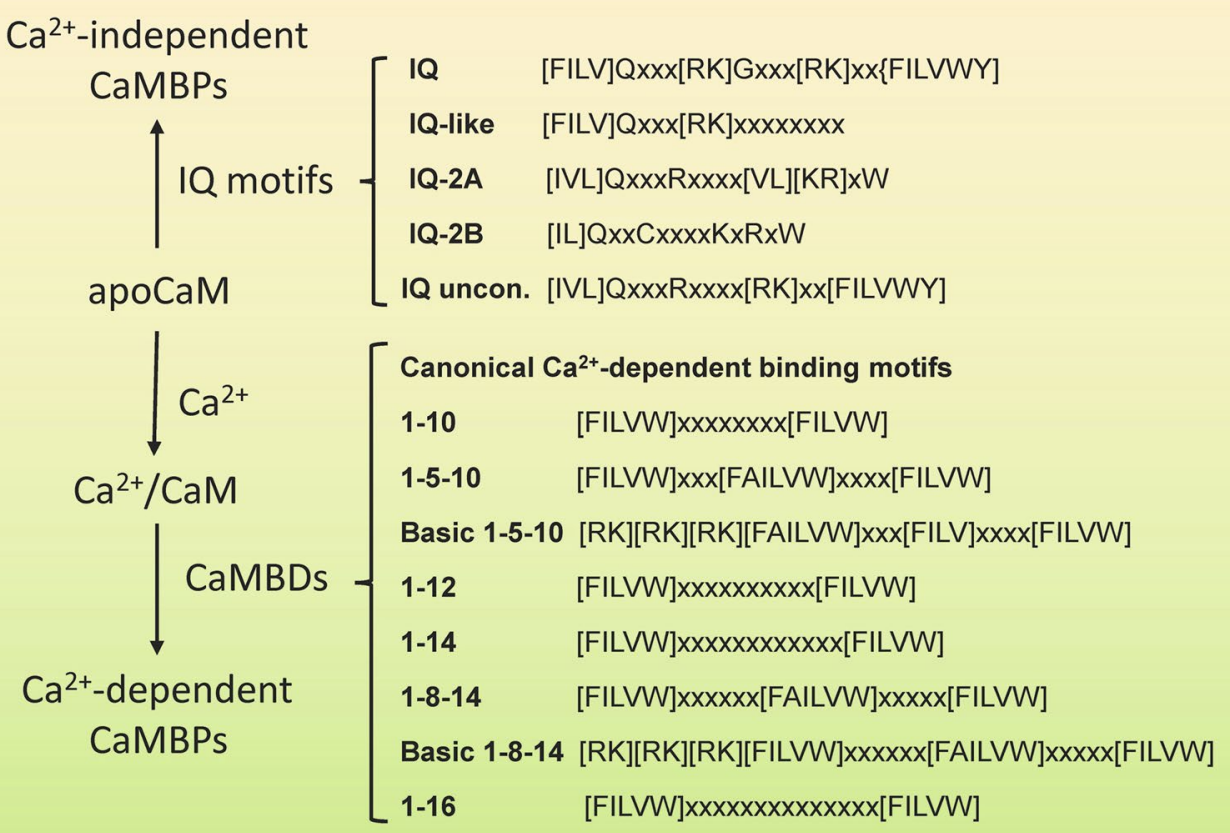

Fig. 2 Calcium-dependent and independent calmodulin binding motifs. CaM, calmodulin; CaMBPs, CaM-binding proteins; CaMBDs, CaM-binding domains. Amino acids: A, Alanine; R, Arginine; Q, Glutamine; I, Isoleucine; L, Leucine; K, Lysine; F, Phenylalanine; W, Tryptophan; Y, Tyrosine; $V$, Valine; X, Any

(Fig. 3). Only one protein was found to contain calciumindependent IQ motifs (NLRP3). Details on the analyses are provided below.

\section{Neuroinflammatory risk factor proteins}

Our analysis revealed the presence of CaMBDs in multiple GWAS neuroinflammation risk factor proteins (Fig. 3). ABCA7 has a two CaMBDs. The previously detected CaMBD (1221LQALLLKRFLLARRSRRGLF1240) contains five calcium-binding motifs (three 1-10, one 1-5-10, one 1-14). The newly identified CaMBD (1401QGLKTKKWVNEVRYGGFSLG1420) [42] has two 1-10 and one 1-5-10 motif. $A B C A 1$, a related $A B C$ transporter involved in neuroinflammation, is a proven $\mathrm{CaMBP}$ with an experimentally verified 1-5-8-14 binding motif that protects the protein from degradation [26].

CLU and CD33 each possess a single CaMBD. The putative CaMBD in CLU (33VAERLTRKYNELLKSYQWKM352) contains three motifs (two 1-12, one 1-14) while CD33 contains six (two $1-10$, two $1-12$, two 1-14) (Fig. 3). CR1 has a CaMBD (1090VVTYRCNLGSRGRKVFEL1107) with a single 1-16 motif. The CaMBD of CR1 is almost identical to three other repeated 18 -amino acid sequences within the protein at positions 207, 657 and 1560. While these other repeats are not recognized as binding domains by a scan via the Calmodulin Target Database, each of these sequences contains both 1-14 and 1-16 motifs found in the validated 10901107 CaMBD. EPHA1 has three motifs (1-12, 1-14, 1-16) within a single CaMBD (167NVERCSLGRLTRRGLYLA184). These results for CR1 and EPHA1 vary slightly from a previous study [42]. The risk factor MS4A proteins also have CaM-binding regions. The single CaMBD in MS4A6A (101LSIATEKRLTKLLVH115) has five different motifs (two 1-10, two 1-12, one 1-14), three more than previously detected [42]. Also, in contrast to previous results, a reanalysis of MS4A4E revealed two CaMBDs. The first (28HSYLCKGLQEKFFKRKPKV6) bears two motifs $(1-10,1-12)$ while the second (107NYLKNLSWRIMGSYLCF123) has four (two 1-12, one $1-14$, one $1-5-10$ ).

\section{PILRA}

PILRA contains one CaMBD (208IMILGLICLLRWRRRKGQQRT229) with two binding motifs (1-10, 1-510) (Fig. 3). While insights have been gained into receptor ligands for PILRA, nothing has been revealed about its downstream signaling events or the role of calcium and $\mathrm{CaM}$ in its function.

\section{TREM2}

The presence of a single CaMBD (62RVVSTHNLWLLSFLRRWNG80) within which multiple classical binding motifs are present (two $1-10$, one $1-12$, one $1-16$ ) 


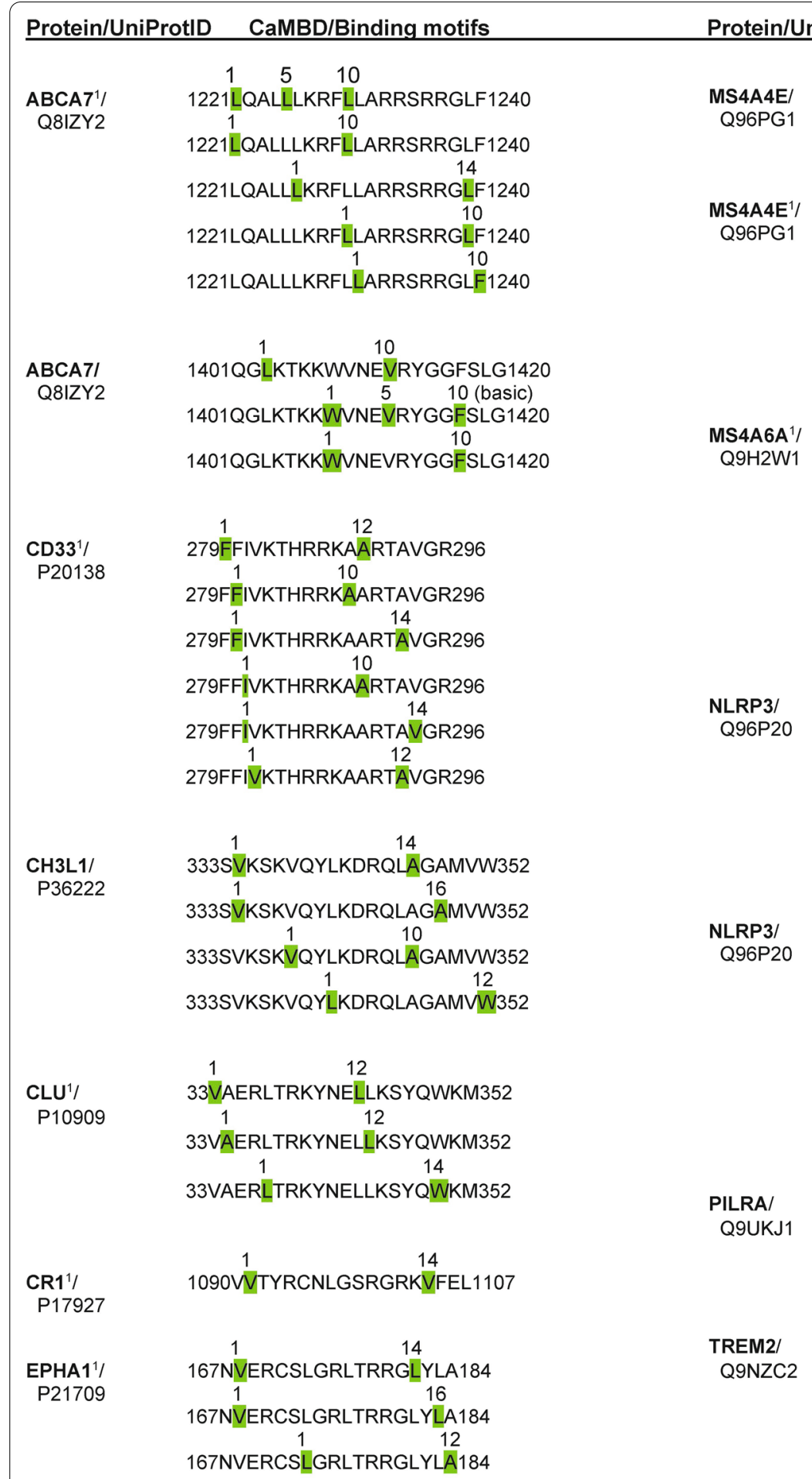

Fig. 3 Calcium-dependent calmodulin binding domains and motifs identified in human neuroinflammation proteins. $A B C A 7$, ATP-binding cassette transporter subfamily A member A7; CD33, Myeloid cell surface antigen CD33; CH3L1/YKL-40, Chitinase-3-like protein 1; CLU, Clusterin; CR1, Complement receptor type 1; EPHA1, Ephrin type-A receptor 1; M4A4E, Membrane-spanning 4-domains subfamily A member 4E; M4A6A, Membrane-spanning 4-domains subfamily A member 6A; NLRP3, NACHT, LRR and PYD domains-containing protein 3; PILRA, Paired immunoglobulin-like type 2 receptor alpha; TREM2, Triggering receptor expressed on myeloid cells 2. 'From O'Day, 2015; reanalyzed here. Green highlights: hydrophobic amino acids associated with binding motifs 
were found in human TREM2 (Fig. 3). This CaMBD falls outside of the AD TREM2 modifier mutation R62H (https://www.alzforum.org/mutations/trem2). Interestingly, T66M, a pathogenic mutation for an FTD-like syndrome, does fall within the domain but this amino acid change does not affect the CaMBD prediction [33]. On the other hand, this binding sequence is in the extracellular portion of the molecule and thus would be present in shed fragments. The role of extracellular CaM is detailed elsewhere but this may suggest that extracellular CaM should be considered in future studies on the role of this small calcium-binding protein in neurodegeneration [45].

\section{NLRP3 inflammasomes}

Two closely juxtaposed putative CaMBDs, CaMBD1 (564ENYGKFEKGYLIFVVRFLFGLVNQERT589) and CaMBD2 (603QIRLELLKWIEVKAKAKKLQIQ624) were revealed in human NLRP3 (Fig. 3). CaMBD1 contains four binding motifs (two 1-10, one 1-14, one 1-16) while CaMBD2 had 5 motifs (two $1-10$, one $1-12$, one 1-14, one 1-16). In addition, a single IQ-like motif (322WQKAERGDILLSSL335) was detected. Thus, it may be possible to use CaM antagonists to directly inhibit NLRP3 function to restore aspects of vascular dementia.

\section{Chitinase 3-like I}

While experimental studies remain to be carried out, a Calmodulin Target Database search and sequence analysis reveals that CH3L1 contains one potential 20-amino acid CaMBD (333SVKSKVQYLKDRQLAGAMVW352) with multiple motifs (one 1-10, one 1-12, one 1-14, one 1-16) (Fig. 3).

\section{The association of proven and putative calmodulin binding proteins with neuroinflammation}

Previously, a central role for CaM and its CaMBPs has been shown for all phases of AD [42-44]. Here, we examined proteins identified by others that are critical to neuroinflammation and other neurodegenerative events involved not only in AD but also in HD, LBD, PD, FTD, MS and other neurodegenerative diseases [18, 19, 22, 50]. The presence of presumptive CaMBDs were identified in 11 proteins linked to neuroinflammation (ABCA7, CD33, CH3LI, CLU, CR1, EPHA1, MS4A4E, MS4A6A, NLRP3, PILRA, TREM2) (Fig. 3). Each of these proteins is linked to one or more neurodegenerative diseases (Fig. 4). For example. apolipoprotein E (APOE) is a neuroinflammatory risk factor CaMBP for AD, ALS, FTD, LBD and PD but not HD or MS. APOE has also been linked to BD, a family of neurodegenerative disorders clinically known as the neuronal ceroid lipofuscinoses (NCLs), in which CaMBPs have been predicted to play a significant role

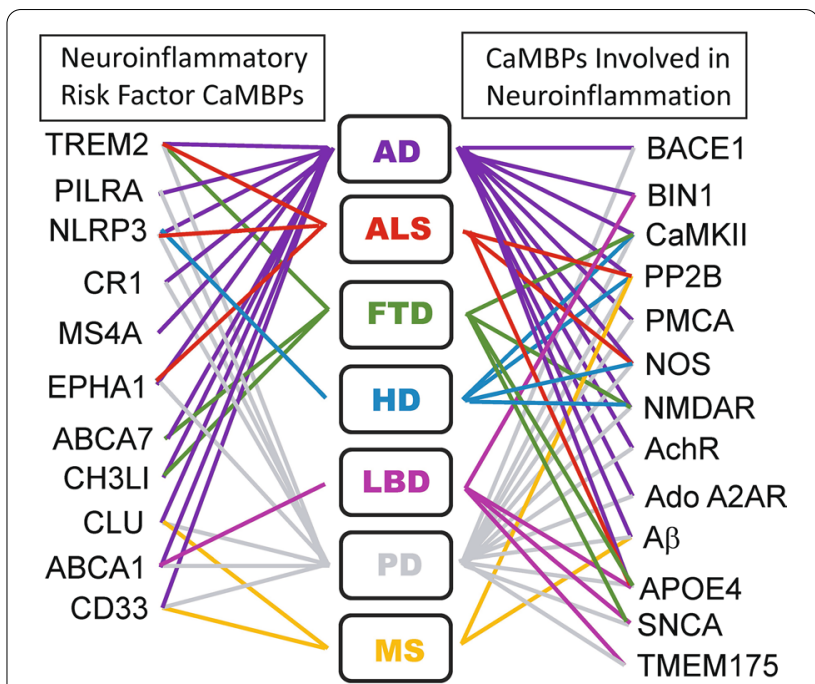

Fig. 4 Calmodulin binding proteins linked to neuroinflammation in specific neurodegenerative diseases. See text for details

$[25,52]$. In addition, there is strong genetic overlap of the NCLs with AD, PD, and FTD [2, 11, 14, 16, 49, 62]. In contrast, the CaMBP CLU is linked to AD, PD and MS. The role of TREM2, which is involved in AD, ALS, FTD and PD, has been recently reviewed [28]. Thirteen other previously identified CaMBPs, not classed as risk factors, have been associated with neuroinflammation in a diversity of neurodegenerative diseases: BACE1, BIN1, CaMKII, PP2B, PMCA, NOS, NMDAR, AchR, Ado A2AR, A $\beta$, APOE, SNCA, TMEM175 [5, 6, 8, 9, 12, 13, 21, 23, 29, 34, 36, 42, 44, 67] (Fig. 4). These CaMBPs also show a significant degree of overlap with different diseases. For example, while the CaMBP BACE1 functions in $\mathrm{AD}$ and $\mathrm{PD}, \mathrm{PP} 2 \mathrm{~B}$ is associated with $\mathrm{AD}, \mathrm{ALS}, \mathrm{HD}, \mathrm{PD}$ and MS. In total, two dozen proven or potential CaMBPs have a central involvement in neuroinflammatory events underlying multiple major neurodegenerative diseases. While many of these proteins are shown to be involved in neuroinflammation in multiple neurodegenerative diseases, this likely is underestimate that can only be clarified as more risk factor and other neuroinflammatory proteins are examined in a greater diversity of neurodegenerative events and diseases.

\section{The therapeutic potential of targeting calmodulin binding} proteins in neurodegenerative disease

CaM and CaMBP based therapies have been used for decades and recently there has been an uptick not only in their use but in new approaches to using them. Numerous $\mathrm{CaM}$ targeting pharmaceuticals have been proven to be safe and effective for use. Both novel and traditional CaM 
antagonists (e.g., (trifluoperazine, tamoxifen) have been successfully used to treat a diversity of cancers including pancreatic cancer and cancer-dependent events such as angiogenesis [30, 66]. The immunosuppressant drug FK506 (Tacrolimus), which is an inhibitor of the classic CaMBP calcineurin, has long been used to prevent organ rejection after transplant surgery (e.g., [57]). In multiple studies, inhibition of calcineurin with FK506 have been proven to reduce plaque burden, restore memory deficits and reduce the incidence of dementia in humans and mouse models $[24,57]$. The treatment of a Huntington's mouse model (R6/2) with a peptide derived from the CaM sequence resulted in neuroprotection apparently through the inhibition of CaM binding to the huntingtin protein [15].

The importance of neuroinflammation in neurodegenerative disease is emphasized by the recent increased focus on anti-inflammatory treatments in dozens of ongoing clinical trials [10]. Many of these investigations focus on targets that are known CaMBPs including $A \beta$, tau, PP2B, NMDAR and AchR. Add to this, several targets are presumptive CaMBPs with identified binding motifs that are also in clinical trials: TREM2, APP and $\alpha$-Syn. In addition, there are Phase 2 clinical trials focusing on the herbal remedy curcumin, which has been shown to bind to CaM. The flavonoid quercetin was identified in the 1980s as a CaMBP and a Phase 2 clinical study using it and a tyrosine kinase inhibitor is in the works. Hopefully if researchers find some success with any of these potential pharmaceuticals they will examine the specific role of CaM-binding in drug efficacy.

A review by Nassal et al. [40] points to ways a specific CaMBP, like CaMKII, can be targeted effectively to achieve a meaningful result. Since CaMKII is an important CaMBP in neuroinflammation and neurodegeneration, this example is appropriate with the essence of the information applicable to other CaM/CaMBP targets involved in neurodegeneration (e.g., [17, 43, 44]). Pharmaceuticals can be chosen that target a specific state of the CaMBP. KN-93 is an allosteric inhibitor of CaM binding CaMKII in its inactive state while AS105, GS-680, and RA306 are ATP-competitive inhibitors of activated CaMKII [40]. CaMKIItide and other peptide inhibitors (e.g., CN19o) are useful but issues of delivery and bioavailability exist. It is possible to overcome challenges in delivery via viral gene delivery and the use of nanoparticles [40]. Wang et al. [61] have used polysialic acid-based micelles to effectively cross the blood-brain barrier to deliver a CaM antagonist (DY-9836) for the treatment of vascular dementia. Their CaM inhibition research on the treatment of vascular dementia and bilateral carotid artery stenosis led to cognitive improvements possibly via the inhibition of nitric oxide overproduction (i.e., nitrosative stress) and inflammasome activation events involving the CaMBPs calcineurin and CaMKII. Finally, RNA interference, antisense oligonucleotides, small interfering RNA, and miRNAs offer alternative approaches to preventing CaMKII function [40]. These studies support the concept of targeting CaM and its binding proteins and provide multiple approaches for doing so. The goal now is to develop therapies that target specific CaMBPs linked to critical common events in neuroinflammation.

\section{Conclusions}

Previous research, coupled with the analysis carried out here using the Calmodulin Target Database, has identified at least two dozen proven or putative CaMBPs that are central to neuroinflammation in multiple neurodegenerative diseases. Each CaMBP contains two or more binding domains with one or more classical binding motifs further supporting the binding of these proteins to CaM. Importantly, multiple pharmaceuticals targeting CaM and CaMBPs have been successfully used to treat several diseases indicating that clinical trials targeting neurodegenerative calmodulin binding proteins could be initiated immediately.

\begin{abstract}
Abbreviations
ABCA1: ATP-binding cassette subfamily A member 1; ABCA7: ATP-binding cassette subfamily A member 7; AD: Alzheimer's disease; ALS: Amyotrophic lateral sclerosis; BD: Batten disease; CaM: Calmodulin; CaMBD: Calmodulin binding domain; CaMBP: Calmodulin binding protein; CD33: Myeloid cell surface antigen CD33; CH3L1/YKL-40: Chitinase-3-like protein I; CLU: Clusterin; CR1: Complement receptor type 1; EPHA1: Ephrin type-A receptor 1; FTD: Frontotemporal dementia; HD: Huntington's disease; LBD: Lewy body dementia; MS: Multiple sclerosis; MS4A: Membrane-spanning 4-domains subfamily A; NCL: Neuronal ceroid lipofuscinosis; NLRP3: NACHT, LRR and PYD domains-containing protein 3; PD: Parkinson's disease; PILRA: Paired immunoglobin like type 2 receptor alpha; TREM2: Triggering receptor expressed on myeloid cells 2.
\end{abstract}

\section{Acknowledgements \\ None.}

\section{Authors' contributions}

DOD conceptualized the paper, analyzed the data and wrote the manuscript; $\mathrm{RJH}$ edited the manuscript, added content and provided funding. Both authors read and approved the final manuscript.

\section{Authors' information}

$\mathrm{DHO}$ is Professor Emeritus in the Department of Cell and Systems Biology at the University of Toronto and the Department of Biology at the University of Toronto Mississauga. His research focusses on the role of calmodulin binding proteins in biological events and neurodegenerative diseases. RJH is an Associate Professor in the Department of Biology at Trent University. His lab studies the molecular and cellular mechanisms underlying Batten disease.

\section{Funding}

This work was supported by a Discovery Grant from the Natural Sciences and Engineering Research Council of Canada (RGPIN-2018-04855 to RJH). The

funder had no role in the design of the study, collection, analysis and interpretation of data, or in writing the manuscript. 


\section{Availability of data and materials}

All data generated or analyzed during this study are included in this published article.

\section{Declarations}

Ethics approval and consent to participate

Not applicable.

\section{Consent for publication}

Not applicable.

\section{Competing interests}

There are no financial or non-financial competing interests.

\section{Author details}

${ }^{1}$ Cell and Systems Biology, University of Toronto, Toronto, ON M5S 3G5, Canada. ${ }^{2}$ Department of Biology, University of Toronto Mississauga, Mississauga, ON L5L 1C6, Canada. ${ }^{3}$ Department of Biology, Trent University, 1600 West Bank Drive, Peterborough, ON K9L 0G2, Canada.

\section{Received: 25 July 2021 Accepted: 15 February 2022}

\section{Published online: 04 March 2022}

\section{References}

1. Aikawa T, Holm ML, Kanekiyo T. ABCA7 and pathogenic pathways in Alzheimer's disease. Brain Sci. 2018:8:27.

2. Arrant AE, Onyilo VC, Unger DE, Roberson ED. Progranulin gene therapy improves lysosomal dysfunction and microglial pathology associated with frontotemporal dementia and neuronal ceroid lipofuscinosis. J Neurosci. 2018:38:2341-58.

3. Behnke V, Langmann T. Neuroinflammation in neuronal ceroid lipofuscinosis. Ophthalmologe. 2021;118:98-105.

4. Berrocal M, Sepulveda MR, Vazquez-Hernandez M, Mata AM. Calmodulin antagonizes amyloid- $\beta$ peptides-mediated inhibition of brain plasma membrane $\mathrm{Ca}(2+)$-ATPase. Biochim Biophys Acta. 2012;1822:961-9.

5. Boczek T, Sobolczyk M, Mackiewicz J, Lisek M, Ferenc B, Guo F, Zylinska L. Crosstalk among calcium ATPases: PMCA, SERCA and SPCA in mental diseases. Int J Mol Sci. 2021;22:2785.

6. Bohush A, Leśniak W, Weis S, Filipek A. Calmodulin and its binding proteins in Parkinson's disease. Int J Mol Med. 2021;22:2016.

7. Bright F, Werry EL, Dobson-Stone C, Piguet O, Ittner LM, Halliday GM Hodges JR, Kiernan MC, Loy CT, Kassiou M, Kril JJ. Neuroinflammation in frontotemporal dementia. Nat Rev Neurol. 2019:15:540-55.

8. Chavez SE, O'Day DH. Calmodulin binds to and regulates the activity of beta-secretase (BACE1). Curr Res Alz Dis. 2007;1(1/2):37-47.

9. Corbacho I, Berrocal M, Török K, Mata AM, Gutierrez-Merino C. High affinity binding of amyloid $\beta$-peptide to calmodulin: Structural and functional implications. Biochem Biophys Res Commun. 2017:486:992-7.

10. Cummings J, Lee G, Zhong K, Fonseca J, Taghva K. Alzheimer's disease drug development pipeline: 2021. Alzheimers Dement. 2021;7:e12179.

11. Dearborn JT, Harmon SK, Fowler SC, O'Malley KL, Taylor GT, Sands MS, Wozniak DF. Comprehensive functional characterization of murine infantile Batten disease including Parkinson-like behavior and dopaminergic markers. Sci Rep. 2015:5:12752.

12. Deckel AW. Nitric oxide and nitric oxide synthase in Huntington's disease. J Neurosci Res. 2001;64:99-107.

13. Deckel AW, Elder R, Fuhrer G. Biphasic developmental changes in $\mathrm{Ca} 2+/$ calmodulin-dependent proteins in R6/2 Huntington's disease mice. NeuroReport. 2002:919:70-81.

14. Deng H, Xiu X, Jankovic J. Genetic convergence of Parkinson's disease and lysosomal storage disorders. Mol Neurobiol. 2015;51:1554-68.

15. Dudek NL, Dai Y, Muma NA. Neuroprotective effects of calmodulin peptide 76-121aa: disruption of calmodulin binding to mutant huntingtin. Brain Pathol. 2010;20:176-89.

16. Geier EG, Bourdenx M, Storm NJ, Cochran JN, Sirkis DW, Hwang JH, Bonham LW, Ramos EM, Diaz A, Van Berlo V, Dokuru D, Nana AL, Karydas A, Balestra ME, Huang Y, Russo SP, Spina S, Grinberg LT, Seeley WW, Myers
RM, Miller BL, Coppola G, Lee SE, Cuervo AM, Yokoyama JS. Rare variants in the neuronal ceroid lipofuscinosis gene MFSD8 are candidate risk factors for frontotemporal dementia. Acta Neuropathol. 2019;137:71-88.

17. Ghosh A, Geise KP. Calcium/calmodulin-dependent kinase II and Alzheimer's disease. Mol Brain. 2015:8:78.

18. Govindarajan V, de Rivero Vaccari JP, Keane RW. Role of inflammasomes in multiple sclerosis and their potential as therapeutic targets. J Neuroinflamm. 2020;17:260.

19. Guo H, Callaway JB, Ting JP. Inflammasomes: mechanism of action, role in disease, and therapeutics. Nat Med. 2015;21:677-87.

20. Guzman-Martinez L, Maccioni RB, Andrade V, Navarrete LP, Pastor MG, Ramos-Escobar N. Neuroinflammation as a common feature of neurodegenerative disorders. Front Pharmacol. 2019;10:1008.

21. Holbrook JA, Jarosz-Griffiths HH, Caseley E, Lara-Reyna S, Poulter JA, Williams-Gray CH, Peckham D, McDermott MF. Neurodegenerative disease and the NLRP3 Inflammasome. Front Pharmacol. 2021;12:643254

22. Hampel H, Caraci F, Cuello AC, Caruso G, Nisticò R, Corbo M, Baldacci F, Toschi N, Garaci F, Chiesa PA, Verdooner SR, Akman-Anderson L, Hernández F, Ávila J, Emanuele E, Valenzuela PL, Lucía A, Watling M, Imbimbo BP, Vergallo A, Lista S. A path toward precision medicine for neuroinflammatory mechanisms in Alzheimer's disease. Front Immunol. 2020;11:456.

23. Heneka MT, Carson MJ, El Khoury J, Landreth GE, Brosseron F, Feinstein DL, Jacobs AH, Wyss-Coray T, Vitorica J, Ransohoff RM, Herrup K, Frautschy SA, Finsen B, Brown GC, Verkhratsky A, Yamanaka K, Koistinaho J, Latz E, Halle A, Petzold GC, Town T, Morgan D, Shinohara ML, Perry VH, Holmes C, Bazan NG, Brooks DJ, Hunot S, Joseph B, Deigendesch N, Garaschuk O, Boddeke E, Dinarello CA, Breitner JC, Cole GM, Golenbock DT, Kummer MP. Neuroinflammation in Alzheimer's disease. Lancet Neurol. 2015;14:388-405.

24. Hong HS, Hwang JY, Son SM, Kim YH, Moon M, Inhee MJ. FK506 reduces amyloid plaque burden and induces MMP-9 in ABPP/PS1 double transgenic mice. J Alzheimers Dis. 2010;22:97-105.

25. Huber RH. Altered protein secretion in Batten disease. Dis Mod Mech. 2021;14:dmm049152.

26. Iwamoto N, Lu R, Abe-Dohmae S, Yokoyama S. Calmodulin interacts with ATP binding cassette transporter A1 to protect from calpain-mediated degradation and upregulates high-density lipoprotein generation. Arterioscler Thromb Vasc Biol. 2010:30:1446-52.

27. Jain MK, Bhat R. Modulation of human a-synuclein aggregation by a combined effect of calcium and dopamine. Neurobiol Dis. 2014:63:115-28.

28. Jay TR, von Saucken VE, Landreth GE. TREM2 in neurodegenerative diseases. Mol Neurodegener. 2017:12:56

29. Jiménez-Jiménez FJ, Alonso-Navarro H, Herrero MT, García-Martín E, Agúndez JA. An update on the role of nitric oxide in the neurodegenerative processes of Parkinson's disease. Curr Med Chem. 2016;23:2666-79.

30. Jung HH, Kim JH, Shim JS, Kwon HJ. A novel Ca2+/calmodulin antagonist $\mathrm{HBC}$ inhibits angiogenesis and down-regulated hypoxia-inducible factor. J Biol Chem. 2010;285:25867-74.

31. Khachaturian ZS. Towards theories of brain aging. In: Kay DS, Burrows GW, editors. Handbook of studies on psychiatry and old age. Amsterdam: Elsevier; 1984. p. 7-30.

32. Khachaturian ZS. Calcium hypothesis of Alzheimer's disease and brain aging. Ann NY Acad Sci. 1994:747:1-11.

33. Kleinberger G, Brendel M, Mracsko E, Wefers B, Groeneweg L, Xiang X, Focke C, Deußing M, Suárez-Calvet M, Mazaheri F, Parhizkar S, Pettkus N, Wurst W, Feederle R, Bartenstein P, Mueggler T, Arzberger T, Knuesel I, Rominger A, Haass C. The FTD-like syndrome causing TREM2 T66 M mutation impairs microglia function, brain perfusion, and glucose metabolism. EMBO J. 2017:36:1837-53.

34. Lange J, Lunde KA, Sletten C, Møller SG, Tysnes OB, Alves G, Larsen JP, Maple-Grødem J. Association of a BACE1 gene polymorphism with Parkinson's disease in a Norwegian population. Parkinsons Dis. 2015;2015:973298.

35. Lenzi C, Ramazzina I, Russo I, Filippini A, Bettuzzi S, Rizzi F. The downregulation of clusterin expression enhances the asynuclein aggregation process. Int J Mol Sci. 2020:21:7181.

36. Lim EW, Aarsland D, Ffytche D, Taddei RN, van Wamelen DJ, Wan YM, Tan EK, Ray Chaudhuri K, Kings Parcog groupMDS Nonmotor study group. Amyloid- $\beta$ and Parkinson's disease. J Neurol. 2019;266:2605-19.

37. Liu CY, Wang X, Liu C, Zhang HL. Targeting of microglial activation: new therapeutic approach. Front Cell Neurosci. 2019;13:514. 
38. Lyssenko NN, Praticó D. ABCA7 and the altered lipidostasis hypothesis of Alzheimer's disease. Alz Dement. 2020;17:164-74.

39. Mruk K, Farley BM, Ritacco AW, Kobertz WR. Calmodulation meta-analysis: predicting calmodulin binding via canonical motif clustering. J Gen Physiol. 2014;144:105-14.

40. Nassal D, Gratz D, Hund TJ. Challenges and opportunities for therapeutic targeting of calmodulin kinase in heart. Front Pharmacol. 2020;1 1:35.

41. O'Day DH, Myre MA. Calmodulin-binding domains in Alzheimer's disease proteins: extending the calcium hypothesis. Biochem Biophys Res Commun. 2004;230:1051-4.

42. O'Day DH, Eshak K, Myre MA. Calmodulin binding proteins and Alzheimer's disease: a review. J Alz Dis. 2015;46:553-69.

43. O'Day DH. Alzheimer's disease: a short introduction to the calmodulin hypothesis. AIMS Neurosci. 2019;6:231-9.

44. O'Day DH. Calmodulin binding proteins and Alzheimer's disease: Biomarkers, regulatory enzymes and receptors that are regulated by calmodulin. Int J Mol Sci. 2020;21:7344.

45. O'Day DH, Huber RJ, Suarez A. Extracellular calmodulin regulates growth and CAMP-mediated chemotaxis in Dictyostelium discoideum. Biochem Biophys Res Commun. 2012:425:750-4.

46. Palpagama TH, Waldvogel HJ, Faull RJM, Kwakowsky A. The role of microglia and astrocytes in Huntington's disease. Front Mol Neuro. 2019;12:258

47. Poejo J, Salazar J, Mata AM, Gutierrez-Merino C. The relevance of amyloid b-calmodulin complexation in neurons and brain degeneration in Alzheimer's disease. Int J Mol Sci. 2021;22:496.

48. Popugaeva E, Pchitskaya E, Bezprozvanny I. Dysregulation of neuronal calcium homeostasis in Alzheimer's disease - a therapeutic opportunity? Biochem Biophys Res Commun. 2017;483:998-1004.

49. Qureshi YH, Patel VM, Berman DE, Kothiya MJ, Neufeld JL, Vardarajan B, Tang M, Reyes-Dumeyer D, Lantigua R, Medrano M, Jiménez-Velázquez IJ, Small SA, Reitz C. An Alzheimer's disease-linked loss-of-function CLN5 variant impairs cathepsin D maturation, consistent with a retromer trafficking defect. Mol Cell Biol. 2018;38:e0011-18.

50. Querol-Vilaseca M, Colom-Cadena M, Pegueroles J, San Martín-Paniello C, Clarimon J, Belbin O, Fortea J, Lleó A. YKL-40 (Chitinase 3-like I) is expressed in a subset of astrocytes in Alzheimer's disease and other tauopathies. J Neuroinflammation. 2017;14:118.

51. Rhoads AR, Friedberg F. Sequence motifs for calmodulin recognition. FASEB J. 1997;11:331-40.

52. Mathavarajah $\mathrm{S}, \mathrm{O}$ 'Day $\mathrm{DH}$, Huber RJ. Neuronal ceroid lipofuscinoses: connecting calcium signalling through calmodulin. Cells. 2018;7:188.

53. Sharma RK, Parameswaran S. Calmodulin-binding proteins: a journey of 40 years. Cell Calcium. 2018;75:89-100.

54. Sommer A, Winner B, Prots I. The trojan horse-neuroinflammatory impact of T cells in neurodegenerative diseases. Mol Neurodegen. 2017:12:78.

55. Surendranathan A, Su L, Mak E, Passamonti L, Hong YT, Arnold R, Vázquez Rodríguez P, Bevan-Jones WR, Brain SAE, Fryer TD, Aigbirhio FI, Rowe JB, O'Brien JT. Early microglial activation and peripheral inflammation in dementia with Lewy bodies. Brain. 2018;141:3415-27.

56. Sweeney MD, Sagare AP, Zlokovic BV. Blood-brain barrier breakdown in Alzheimer disease and other neurodegenerative disorders. Nat Rev Neurol. 2018;14:133-50.

57. Taglialatella G, Rastellini C, Cicalese L. Reduced incidence of dementia in solid organ transplant patients treated with calcineurin inhibitors. J Alz Dis. 2015;47:329-33.

58. Tarczyluk-Wells MA, Salzlechner C, Najafi AR, Lim MJ, Smith D, Platt FM, Williams BP, Cooper JD. Combined anti-inflammatory and neuroprotective treatments have the potential to impact disease phenotypes in Cln3-/- mice. Front Neurol. 2019;10:963.

59. Tidow H, Nissen P. Structural diversity of calmodulin binding to its target sites. FEBS J. 2013;280:5551-65.

60. Troncoso-Escudero P, Parra A, Nassif M, Vidal RL. Outside in: Unraveling the role of neuroinflammation in the progression of Parkinson's disease. Front Neurol. 2018;9:860.

61. Wang R, Yin YX, Mahmood Q, Wang XJ, Gao YP, Gou GJ, Ahmed MM, Kohji F, Du YZ, Han F. Calmodulin inhibitor ameliorates cognitive dysfunction via inhibiting nitrosative stress and NLRP3 signaling in mice with bilateral carotid artery stenosis. CNS Neurosci Ther. 2017;23:818-26.

62. Ward ME, Chen R, Huang HY, Ludwig C, Telpoukhovskaia M, Taubes A, Boudin H, Minami SS, Reichert M, Albrecht P, Gelfand JM, Cruz-Herranz A,
Cordano C, Alavi MV, Leslie S, Seeley WW, Miller BL, Bigio E, Mesulam MM, Bogyo MS, Mackenzie IR, Staropoli JF, Cotman SL, Huang EJ, Gan L, Green AJ. Individuals with progranulin haploinsufficiency exhibit features of neuronal ceroid lipofuscinosis. Sci Transl Med. 2017;9:eeah5642.

63. Xu Y, Kirberger M, Yang JJ. Aspects and prediction of calmodulin binding proteins. Int J Mol Sci. 2021;22:308.

64. Yan YQ, Fang Y, Zheng R, Pu JL, Zhang BR. NLRP3 inflammasomes in Parkinson's disease and their regulation by Parkin. Neuroscience. 2020:446:323-34.

65. Yap KL, Kim J, Truong K, Sherman M, Yuan T, Ikura M. Calmodulin target database. J Struct Funct Genomics. 2000;1:8-14.

66. Yuan K, Yong S, Xu F, Zhou T, McDonald JM, Chen Y. Calmodulin antagonists promote TRA-8 therapy of resistant pancreatic cancer. Oncotarget. 2015;6:25308-19.

67. Zalchick SV, McGrath KM, Caraveo G. The role of $\mathrm{Ca}^{2+}$ signaling in Parkinson's disease. Dis Mod Mech. 2017:10:519-35.

\section{Publisher's Note}

Springer Nature remains neutral with regard to jurisdictional claims in published maps and institutional affiliations.
Ready to submit your research? Choose BMC and benefit from:

- fast, convenient online submission

- thorough peer review by experienced researchers in your field

- rapid publication on acceptance

- support for research data, including large and complex data types

- gold Open Access which fosters wider collaboration and increased citations

- maximum visibility for your research: over $100 \mathrm{M}$ website views per year

At BMC, research is always in progress.

Learn more biomedcentral.com/submissions 